\title{
O trabalho como possibilidade de (re)inserção social do usuário de um Centro de Atenção Psicossocial na perspectiva da equipe e do usuário
}

\author{
Work as a possibility of social (re)inclusion for users of a \\ Psychosocial Attention Center (PAC) in their own perspective \\ and the team's
}

\author{
Kelen Patrícia Bürke \\ Hospital de Clínicas de Porto Alegre - HCPA, Porto Alegre, Rio Grande do Sul, Brasil \\ Desirée Luzardo Cardozo Bianchessi \\ Hospital de Clínicas de Porto Alegre - HCPA, Porto Alegre, Rio Grande do Sul, Brasil
}

\begin{abstract}
RESUMO
O presente artigo busca compreender as possibilidades de (re)inserção social do usuário do CAPS, através do trabalho, a partir da perspectiva do usuário e da equipe. O estudo ocorreu no CAPS II do Hospital de Clínicas de Porto Alegre/RS, no qual foram entrevistados profissionais e usuários. Utilizou-se uma metodologia qualitativa e exploratória, sendo a análise dos dados realizada através do método Análise de Conteúdo, utilizando-se temas para o agrupamento dos achados. Os resultados apontam para um sentido do trabalho enquanto um meio de ocupar a mente, produzir vínculos, auxiliar na autoestima e enquanto vivências de satisfação e prazer. Entretanto, o trabalho enquanto possibilidade de (re)inserção social ainda apresenta muitas limitações, impostas pela sociedade capitalista, sendo necessário repensar modos de trabalhar que favoreçam a criatividade e as possibilidades do sujeito no resgate da sua subjetividade e na busca pela cidadania, promovendo saúde mental.
\end{abstract}

Palavras-chave: (Re)inserção Social, Saúde Mental, Trabalho, Centro de Atenção Psicossocial.

\begin{abstract}
The present article seeks to understand the possibilities of social (re)inclusion of PACs' users, through work, from the perspective of the user and the teamwork. The study took place at PAC II of the Hospital de Clínicas de Porto Alegre in the state of Rio Grande do Sul, where some professionals and users were interviewed. A qualitative and exploratory methodology was used and data analysis was performed by the method of Content Analysis, using themes for grouping the findings. The results point to a sense of work as a way to occupy the mind, produce links, assist in self-esteem, and as experiences of fulfillment and pleasure. However, the work whereas a possibility of social (re)inclusion still has many limitations imposed by the capitalist society. So, it is necessary to rethink ways of work that encourage creativity and foster the possibilities of the subject in the rescue of his/her
\end{abstract}


subjectivity and in the search for citizenship, and consequently, mental health promotion.

Keywords: Social (Re)inclusion, Mental Health, Work, Psychosocial Attention Center.

\section{I ntrodução}

O movimento pela reforma psiquiátrica atravessa mudanças importantes no cenário brasileiro, buscando a superação do modelo tradicional de assistência ao portador de sofrimento psíquico, através da criação de serviços substitutivos e de uma rede de atenção integral à saúde mental, visando o resgate dos direitos das pessoas que apresentam transtornos psiquiátricos (HIRDES, 2001). Os usuários de serviços de saúde mental que historicamente sofriam com privações de direitos e tratamentos, em determinadas situações desumanas, hoje podem contar com políticas públicas voltadas para o resgate da cidadania. Com a criação destas políticas, as pessoas portadoras de transtornos mentais contam com a atenção de serviços e dispositivos (BRASIL, 1992) calcados no conceito de saúde preconizado pela lei $\mathrm{n}^{\circ} 8080$ de 19 de setembro de 1990 (BRASIL, 1990). Neste conceito de saúde são considerados fatores determinantes e condicionantes, entre outros, a alimentação, moradia, saneamento básico, meio ambiente, trabalho, renda, educação, transporte, lazer e acesso aos bens e serviços essenciais. Este modo de entender a saúde necessita de serviços que busquem desenvolver seu trabalho baseado nos princípios de integralidade, universalidade e equidade.

O Centro de Atenção Psicossocial (CAPS), como parte desta política, é uma estratégia que visa 0 atendimento integral, procurando promover, dentre outros, a (re)inserção social do usuário através do trabalho. Usaremos o termo (re)inserção social como forma de abranger tanto os usuários que nunca trabalharam, como aqueles que já trabalhavam e por algum motivo, seja relacionado ou não a saúde mental, não estão mais inseridos em atividades comuns à vida social, como as laborais.

Portanto, este artigo tem como objetivo abordar a questão da (re)inserção social de usuários de CAPS por meio do trabalho, compreendendo o significado do mesmo a partir do ponto de vista da equipe e dos usuários. Além disso, discutir os aspectos relacionados ao trabalho na promoção da cidadania, em consonância com os preceitos do atendimento em saúde mental. Pretende-se que essa discussão possa contribuir para o avanço da (re)inserção social dos usuários de CAPS, de modo crítico e político. O interesse em pesquisar sobre o assunto surgiu a partir da vivência na Residência 
Integrada Multiprofissional em Saúde, com ênfase em Saúde Mental do Hospital de Clínicas de Porto Alegre.

\section{Método}

Para a realização desta pesquisa, utilizou-se uma metodologia de caráter exploratório-qualitativo (BARDIN, 2002). Entende-se que esse método de pesquisa é o mais apropriado a este tipo de investigação qualitativa, pois busca a compreensão que as pessoas têm sobre o tema abordado e possibilita o seu aprofundamento. A pesquisa foi realizada no Centro de Atenção Psicossocial (CAPS II) do Hospital de Clínicas de Porto Alegre (HCPA). Este CAPS II iniciou suas atividades no ano de 2000, conta com equipe multiprofissional e atende em torno de 120 usuários/mês.

A coleta de dados foi realizada através de entrevista semiestruturada, com a equipe e usuários. Participaram desta pesquisa treze sujeitos, sendo oito profissionais e cinco usuários. Entrevistouse um profissional de cada categoria, conforme definição no projeto, sendo elas: Enfermagem, Terapia Ocupacional, Medicina, Educação Física, Pedagogia, Assistência Social, Técnico de Enfermagem e Auxiliar Administrativo.

O processo de pesquisa foi desencadeado com a apresentação do projeto em reunião de equipe. Nesta ocasião, solicitou-se a indicação dos usuários em tratamento, atentando para os seguintes critérios de inclusão: condições de responder à entrevista e disponibilidade para participar da pesquisa. Foram excluídos usuários com retardo mental grave e que não apresentavam condições psíquicas de responder a entrevista. Com relação aos membros da equipe levou-se em consideração o caráter voluntário para participar da pesquisa, tendo como critério, no mínimo uma entrevista por área profissional.

As entrevistas foram gravadas e posteriormente transcritas e analisadas através da metodologia da Análise de Conteúdo (BARDIN, 2002), utilizando-se a análise temática. Conforme a autora, fazer uma análise temática consiste em descobrir os núcleos de sentido que compõem a comunicação, cuja presença ou frequência de aparição podem ter significado para o objetivo analítico escolhido. Através da leitura do material, foram sendo identificadas as categorias propostas dentro de temas que continham um sentido comum.

Os usuários e os profissionais não foram identificados, preservandose o sigilo das informações. Todos os entrevistados assinaram o Termo de Consentimento Livre e Esclarecido. O projeto de pesquisa foi aprovado no Comitê de Ética do Hospital de Clínicas de Porto Alegre sob o número 11-0070 e atende as normas de pesquisa com seres humanos, cumprimento os princípios éticos contidos 
na Declaração de Helsinki (WORLD MEDICAL ASSOCIATION DECLARATION OF HELSINKI, 2008) e na resolução 196/96 do Conselho Nacional de Saúde (BRASIL, 1996).

\section{Apresentação e discussão dos resultados}

Os resultados serão apresentados e discutidos em dois momentos. Primeiro, a análise realizada nas entrevistas com a equipe, posteriormente a análise das entrevistas com os usuários.

\subsection{Análise das entrevistas da equipe}

A análise das entrevistas com a equipe originou os eixos temáticos e categorias descritos na tabela a seguir.

Tabela 1 - Temas e categorias encontradas da análise dos dados das entrevistas com a equipe

\begin{tabular}{ll}
\hline \multicolumn{1}{c}{ Temas } & \multicolumn{1}{c}{ Categorias } \\
\hline $\begin{array}{l}\text { Compreensão da } \\
\text { equipe sobre o }\end{array}$ & $\begin{array}{l}\text { Processo conjunto dos profissionais com os usuários; depende das } \\
\text { condições da doença; processo gradativo; apropriação do usuário } \\
\text { processo de }\end{array}$ \\
$\begin{array}{ll}\text { dre)inserção social } \\
\text { formas; possibilita autonomia }\end{array}$ \\
$\begin{array}{ll}\text { Percepção sobre o } & \text { Ocupação da mente; produtor de vínculos; autonomia; } \\
\text { papel do trabalho } & \text { autoestima; como prejudicial à saúde; como ameaça ao benefício } \\
\text { da aposentadoria } & \text { Oficina de Geração de Renda; Outras oficinas e outras atividades } \\
\text { Atividades no } & \\
\text { CAPS que } & \\
\text { promovem a } & \\
\text { (re)inserção pelo } \\
\text { trabalho }\end{array}$ \\
\hline
\end{tabular}

Considerando que o trabalho constitui o eixo central desta pesquisa, buscamos compreender de forma mais aprofundada seu sentido e as possibilidades de (re)inserção social por meio deste. Discutimos o tema que se refere à percepção da equipe sobre o papel do trabalho neste processo. Da mesma forma, os sentidos que o usuário atribui ao trabalho, tema originado das entrevistas com estes, o qual será apresentado posteriormente. Todas as falas citadas a seguir são de profissionais da equipe. 
A Percepção da equipe sobre o papel do trabalho revela a compreensão sobre a configuração do trabalho no processo de (re)inserção social do usuário e as dificuldades encontradas. Na tabela 2 apresentam-se as categorias e a frequência de aparição emergidas a partir dos conteúdos trazidos pela equipe nesta temática.

Tabela 2 - Freqüência das categorias originadas do tema Percepção da equipe sobre o papel do trabalho

\begin{tabular}{lcc}
\hline \multicolumn{1}{c}{ Categorias } & $\begin{array}{c}\boldsymbol{N} \text { de } \\
\text { Profissionais }\end{array}$ & $\begin{array}{c}\text { Total de } \\
\text { Ocorrências }\end{array}$ \\
\hline Ocupação da mente & 5 & 10 \\
Autonomia & 3 & 5 \\
Autoestima & 3 & 5 \\
Produtor de vínculos & 4 & 7 \\
Como prejudicial à saúde & 5 & 8 \\
Como ameaça ao benefício da aposentadoria & 5 & 6 \\
\hline
\end{tabular}

As categorias indicam os diferentes modos como a equipe percebe 0 papel do trabalho no processo de (re)inserção social do usuário. O trabalho como ocupação da mente apresenta-se com maior frequência, sendo considerado como um benefício para a saúde do usuário, cumprindo com a função de ocupar seus pensamentos, de forma a não ficar centrado na doença, como identificamos na fala destes profissionais:

“E o trabalho vai ajudar eles, não só o tratamento. A partir do momento que ele se trata e que ele consegue voltar a conviver com as pessoas, o trabalho vai ocupar um espaço pra ele, que não vai pensar na doença...".

“... no caso ele estar trabalhando? É uma questão de ocupar a mente. (...) A partir do momento que ele se trata e que ele consegue voltar a conviver com as pessoas, o trabalho vai ocupar um espaço pra ele que não vai pensar na doença".

$\mathrm{Na}$ história da psiquiatria encontramos essa concepção quando existiam os chamados manicômios (que podem existir ainda hoje), onde muitos pacientes auxiliavam em tarefas no hospital. Amarante 
(2007) traz que Franco Basaglia importou-se com esta questão, propondo que os pacientes internados pudessem desempenhar atividades de trabalho e, que fossem remunerados. Porém a administração do hospital não concordou, pois os considerava "loucos", justificando o trabalho como voluntário e até mesmo terapêutico (laborterapia e ergoterapia).

Franco da Rocha (apud RESENDE, 2001) foi o primeiro a defender o trabalho no hospício, quando escreveu um artigo, em 1889, intitulado - "A questão do trabalho nos hospícios". Neste período pensava-se que a ociosidade era prejudicial, sendo estabelecido o trabalho como um recurso terapêutico, conhecido como tratamento moral. Nos dias atuais, percebe-se a presença dessa compreensão sobre o trabalho como um meio de ocupar a mente e que a ociosidade pode prejudicar a saúde mental das pessoas.

Lima (2004) aponta que o trabalho não foi instituído como medida de sanidade mental somente nos espaços de tratamento dos transtornos mentais, mas a valorização e dignificação do trabalho eram bases para a construção de uma nova sociedade organizada em torno da produção capitalista.

Além da função de ocupação da mente, a equipe também se refere ao trabalho como favorecendo a autonomia, produzindo e estimulando maior independência do usuário.

“Eles não tem nenhum impeditivo (...) eles circulam pelos espaços, eles pegam ônibus, eles vão e vêm sozinhos, são autônomos. Então, aumentar mais ainda essa autonomia pra eles, acho que pra qualquer pessoa, o trabalho é fundamental, acho importante que, sempre que possível a gente possa estar falando isso com eles".

“Eu acho que o que melhorou é autonomia (...). Bom, agora tu escolheste trabalhar, então tu tem que mostrar que tu tem condição pra isso, que tu consegue te organizar, que tu consegue assumir essa responsabilidade"

Dejours (1994) nos ajuda a entender essa função do trabalho dizendo que, se este puder fundamentar-se na autonomia, possibilitando vivências de prazer, poderá ser gerador de sentimentos de gratificação, de realização, reconhecimento, liberdade e valorização. Rodrigues, Marinho e Amorin (2010), em pesquisa realizada, apontam para a necessidade de resgatar a questão do trabalho pelos Centros de Atenção Psicossocial junto aos usuários, não para procurar uma inserção imediata no mundo do trabalho, mas para valorizar esta dimensão da vida, cujo sentido é construído pela história e pela narrativa do próprio sujeito. O trabalho como meio de inclusão social de pessoas portadoras de sofrimento mental se afirma enquanto um direito de cidadania, sendo necessário um aprofundamento sobre o 
papel do CAPS na articulação entre a clínica e a compreensão do trabalho, enquanto um direito e enquanto uma proposta concreta de (re)inserção social além do espaço físico do CAPS.

Entendemos que, na mesma linha de raciocínio do exposto acima, a equipe percebe o trabalho como estímulo para a melhoria da autoestima do usuário, como observamos na fala destes profissionais.

"Bom... quando ele tem uma atividade que realmente o conquiste, ele tem aumento de autoestima. Daí ele se revela melhor, mais autoconfiante, e tenho eu a impressão que a medicação e tudo mais que é feito pra ele melhorar, fica bem mais fácil. Eu acho que melhora muito, a autoestima, o autocuidado."

“... o trabalho também aumenta a autoestima da gente, porque a gente além de poder ganhar, poder ter uma participação, que a gente construiu algo naquele horário, a gente fez alguma coisa realmente naquele tempo que é vivido".

Desta forma, o profissional da equipe fala de um sentido do trabalho para o usuário, mas também para si. Pensar sobre este tema referese a si mesmo e os modos como o trabalho se apresenta em sua vida.

O trabalho para Dejours (1994) funciona como um operador fundamental na construção do sujeito, revelando-se como um mediador privilegiado entre inconsciente e campo social e entre a ordem singular e coletiva. Para ele o trabalho não é apenas um espaço aberto ao investimento subjetivo, é também um espaço de construção de sentido, um espaço de construção da identidade, como forma de continuar o processo de formação da história do sujeito.

Para pensar a subjetividade como modos de agir, pensar, sentir e trabalhar, é necessário refletir sobre como as experiências de trabalho produzem essa construção de subjetividade (CATTANI, 2006). Assim, para que o trabalho opere como construtor de subjetividades é necessário considerar o desejo do usuário, como diz este profissional da equipe:

\footnotetext{
“Como deveria acontecer esse processo de reinserção, considerando assim, as expectativas do usuário, que durante esse processo de tratamento no CAPS, se trabalhasse as possibilidades deles e os desejos. Eu penso que, às vezes, a gente trabalha numa lógica mais capitalista, nessa lógica do trabalho formal, e, às vezes, o olhar do usuário, ele tá pra uma outra lógica".
}

Pensamos como Rodrigues, Marinho e Amorin (2010), que os desafios na reinserção social através do trabalho correspondem ao modelo de 
produção capitalista contemporâneo, que exclui do mundo do trabalho as pessoas consideradas inaptas e/ou improdutivas junto ao mercado, como destacado pela equipe.

Com a intenção de fazer frente a esta lógica, programas de Inclusão Social pelo trabalho foram criados com o objetivo de contribuir para a reabilitação psicossocial e econômica da pessoa com transtorno mental, por meio de sua inserção em oficinas de Geração de Trabalho e Renda ou em grupos associativos, organizados de forma coletiva e participativa, formais ou informais, sendo regidos por diretrizes da Política Nacional de Saúde Mental e da Economia Solidária. Estes programas apóiam a inclusão social, o acesso ao trabalho e renda sob a égide dos direitos humanos, o incremento da autonomia e da emancipação do usuário, desenvolvimento da cooperação e da solidariedade, fortalecimento do coletivo e geração de alternativas concretas (BRASIL, 2011).

O trabalho também é compreendido pela equipe como um produtor de vínculos, podendo auxiliar o usuário nas suas relações sociais.

\begin{abstract}
“... ele foi lá ficou com o (nome) o dia inteiro, o (nome) fez almoço pra ele, pros dois, almoçaram juntos, tá fazendo as duas coisas, tá trabalhando e tá aumentando a rede social dele... Que ele não foi só trabalhar (...) eles fizeram um vínculo, né, um vínculo social..."

“Mas não é só ficar ali produzindo, mas que tenha possibilidade de conviver com outras pessoas. Mas cadê a possibilidade dele sair dali, ou pra vender o produto, ou para conviver, ou para ver outras possibilidades dentro daquilo que ele está aprendendo".
\end{abstract}

Concordamos com Lussi, Matsukura e Hahn (2010), quando se referem ao trabalho como uma prática que promove integração e legitima socialmente os indivíduos, favorecendo o reconhecimento nas diferentes classes sociais, grupos e comunidade, entendendo a oportunidade de voltar a trabalhar como forma de ampliar as possibilidades da inserção social e melhorar níveis de saúde.

Se por um lado o entendimento da equipe de que o trabalho pode trazer benefícios à saúde do usuário, por outro, apontam também que este pode apresentar-se como prejudicial à saúde, manifestando alguns receios e indicando que 0 trabalho pode interferir de modo negativo na vida dos usuários, como observamos nas falas abaixo.

“... o trabalho é um estressor, ele pode ajudar muito, mas também pode atrapalhar, dependendo do nível da doença de cada um. Então assim, o trabalho, eu acho que é a última escala, eu acho que é a última escala de melhora de um paciente. Porque tu conseguir ter um trabalho, ter uma 
responsabilidade com teu trabalho, com as pessoas que estão envolvidas nele, requer muita sanidade mental, que a pessoa esteja muito bem (...). Então mesmo o trabalho informal é estressante, acho que até mais, porque tu não tem nenhuma seguridade, que tu vai adoecer e vai continuar recebendo dinheiro. Tu para de produzir, tu para de ganhar".

Sabe-se que o modo de produção capitalista apresenta-se de forma competitiva e exige dos trabalhadores uma série de cobranças e flexibilizações, que também promovem a exclusão. No cenário do trabalho atual pouco se permite e respeita variações e movimentos espontâneos, característicos da individualidade do ser humano, sendo que as organizações exigem posturas, comportamentos e ritmos, em uma constante tentativa de controle do tempo, dos corpos e das mentes dos trabalhadores (SANTIAGO, 2011)

Hirdes (2011) aponta que o acesso ao trabalho por pessoas portadoras de transtornos mentais ainda é o maior obstáculo à inserção social. A autora entende que, atualmente, conflitos gerados pela competitividade e a geração de empregos provocam uma crescente exclusão do mercado de trabalho. Para que o trabalho possa permitir uma produção de sentido, de vida, de inclusão, de dignidade, de direito e de justiça, é necessário a composição de movimentos que promovam uma maior consciência e uma mudança no modo de compreender aqueles que se apresentam mais vulneráveis às condições sociais.

Uma das respostas à exclusão pelo mercado, por parte dos que não querem uma sociedade movida pela competição, é a proposta da Economia Solidária. Esta é compreendida como uma opção ética, política e ideológica, que se torna prática quando os optantes encontram os de fato excluídos e juntos constroem empreendimentos produtivos, redes de trocas, instituições financeiras, escolas, entidades representativas, etc. (BRASIL, 2005).

Também identificamos que além da exigência da produção capitalista imposta pela sociedade, outras esferas da vida são regidas pelo social, como expressa este profissional.

“É aquilo que a sociedade espera das pessoas, que crescem e que vão trabalhar, ganhar dinheiro, cuidar da sua vida. Então a sensação que eu tenho é que muitos têm essa expectativa de trabalhar, mas pra se aproximar dessa normalidade. Exigem isso pra tu ser normal. Tu tem que estar namorando, tu tem que estar trabalhando".

Zanelli (2004) resgata um conceito formulado por Freud sobre saúde mental como sendo a capacidade de amar e trabalhar. O relato acima traz bem essa concepção, de que estar saudável mentalmente implica que o sujeito consiga conciliar em sua vida o amor e o trabalho. $O$ autor refere que estas são duas grandes áreas na vida do ser humano 
adulto: o amor, traduzido nos afetos, nos amigos, na família e no erotismo; e o trabalho, na profissão, no dinheiro, na classe social, na produção, no consumo. Pelo amor reproduzimo-nos, pelo trabalho produzimo-nos - produzir e reproduzir explicam a nossa existência. 0 indivíduo então, não se realiza em si mesmo, ele somente constrói quando se espelha no outro, no grupo, na sociedade.

Para Canguilhem (2009), o homem só se sente em boa saúde quando se sente mais do que normal, isto é, não apenas adaptado ao meio e às suas exigências, mas também sendo normativo. Em outras palavras, ser normativo é ser capaz de criar novas normas de vida, de ser inventivo. $O$ autor ressalta que num sentido absoluto, a saúde nada mais é que a indeterminação inicial da capacidade de instituição de novas normas biológicas. Desta forma, pensamos que o trabalho, dependendo de suas condições, pode ser um agente transformador da condição de vida em que a pessoa se encontra.

Porém, sabemos que o trabalho pode gerar ansiedades através da exigência do cumprimento de rotinas e normas. A preocupação da profissional, na fala posterior, reflete o cuidado que a equipe precisa ter, com relação à (re)inserção pelo trabalho. O usuário, ao se deparar com o cumprimento das exigências impostas pelo trabalho, pode sentir-se frustrado e isto ser mais prejudicial a sua saúde.

“... tô bem, tô trabalhando... mas só que assim... gera muita angústia porque é uma responsabilidade. Tu tem que acordar no horário certo. Tu tem que bater o cartão no horário certo. Então, essas coisas, acho que acabam gerando uma angústia... de repente começam a chegar atrasado, começam a faltar. Aí eles colocam pra rua. E depois gera mais uma angústia (...) eu sou incapaz. (...) uma frustração na verdade".

Dejours (1994) refere o trabalho como prejudicial à saúde quando este não contempla o desejo do trabalhador, quando as relações de poder e de exploração máxima da força de trabalho, tornam o corpo do trabalhador domesticado e forçado a agir conforme a vontade do outro. Assim, surgem resistências, pondo em conflito o desejo do trabalhador à realidade do trabalho, gerando carga psíquica. O autor diz que é necessário haver um espaço de liberdade entre o homem e o trabalho prescrito, onde sejam possíveis negociações e invenções sobre a organização do trabalho, adaptando-o às suas necessidades e desejos. "Quer dizer, então não pode ser o mundo do trabalho um espaço que ele vá produzir de novo a doença e voltar e fazer tudo de novo".

Considerando estas questões, o encaminhamento do usuário ao trabalho deve ser problematizado, buscando integrar o desejo do usuário com atividades laborais que não prejudiquem o seu espaço de liberdade e criação. Sendo assim, compreendemos que o trabalho 
formal, como está posto atualmente, pode sim ser prejudicial à saúde, exigindo identificar formas alternativas que possibilitem a valorização do trabalho como constituinte da subjetividade, com possibilidades de (re)inserção social.

A repercussão negativa do trabalho para o usuário também é percebida pela equipe quando este se torna uma ameaça à perda do direito ao benefício e/ou aposentadoria, gerando ansiedade frente às necessidades de sustento e de possibilidades de participação na sociedade, como expresso abaixo.

“... e por outro lado, na contramão desse esforço, os próprios pacientes e familiares ficaram com medo, eles não queriam trabalhar porque eles queriam receber a pensão do governo, o benefício do governo (...). Porque eles sabem que o trabalho seria algo mais instável do que eles receberem, essa ajuda governamental, então, pela doença. Eles mesmos não tinham interesse".

“Mas há um cuidado com o benefício sim, porque eu acho que de fato eles precisam manter. O dinheiro possibilita coisas, e não dá pra correr o risco de colocar um benefício que já tá garantido por uma coisa que é incerta".

$\mathrm{Na}$ categoria como ameaça ao benefício/ aposentadoria, esta questão é problematizada. Há uma necessidade de rever as políticas de Assistência Social para pessoas portadoras de transtornos mentais, pois estas engessam o fazer da equipe multiprofissional e o usuário na procura por um trabalho. Estes questionamentos apontados pela equipe mostram as dificuldades para colocação do usuário no trabalho formal e conquista de maior autonomia, pois representa um risco para sua segurança financeira, consequentemente no gerenciamento da sua vida.

Em pesquisa realizada com usuários de CAPS (Rodrigues, MARINHO E AMORIN, 2010), os resultados apontam que o benefício tem contribuído para a realização de projetos de trabalho, para aperfeiçoamento pessoal através de investimentos culturais e informações, para a inclusão na família, pois muitas vezes o benefício entra como uma contribuição na renda familiar e para a inclusão na rede social.

Na nossa sociedade capitalista, onde a hipervalorização da produção e do lucro constituem as organizações, percebemos o quão é difícil buscar a (re)inserção do usuário. Essa situação exige das equipes, juntamente com os usuários, familiares e com a sociedade, a necessidade de pensar alternativas que possibilitem a (re)inserção do usuário de forma a auxiliá-lo na conquista da sua cidadania.

\subsection{Análise das entrevistas dos usuários}


Com relação às entrevistas realizadas com os usuários, foram identificados dois temas que apresentamos na tabela a seguir.

Tabela 3 - Temas e categorias encontradas da análise dos dados das entrevistas com os usuários

\begin{tabular}{ll}
\hline \multicolumn{1}{c}{ Temas } & \multicolumn{1}{c}{ Categorias } \\
\hline Sentidos do trabalho & $\begin{array}{l}\text { Auxiliar na autonomia; Ocupação da mente/ } \\
\text { tempo; Possibilita relações sociais; Proporciona } \\
\end{array}$ \\
& prazer; Autoestima \\
Compreensão do usuário sobre o & Depende da estabilidade da doença; Função do \\
processo de (re)inserção social & CAPS \\
\hline
\end{tabular}

Como já descrito anteriormente, abordaremos aqui o tema Sentidos do trabalho através do qual podemos visualizar os possíveis sentidos que os usuários do CAPS expressam com relação ao trabalho e as possibilidades de (re)inserção através deste. Na tabela 4 são apresentas as categorias originadas da análise de conteúdo referente a este tema.

Tabela 4 - Freqüência das categorias originadas do tema Sentidos do Trabalho

\section{Categorias}

Auxiliar na autonomia

Ocupação da mente/ tempo

Possibilita relações sociais

Proporciona prazer

Autoestima

Número de usuários Total de ocorrências

5

5

4

4

3
8

7

10

9

5

As categorias indicam os diferentes modos com que o usuário percebe o trabalho nas suas vidas e a função que ocupa com relação à sua doença. As falas aqui citadas foram retiradas das entrevistas com os usuários. A categoria com maior ocorrência se refere ao trabalho como um meio que possibilita relações sociais. Isto traz um importante indicativo, pois sabemos que uma das dificuldades 
relacionadas ao adoecimento mental refere-se às limitações dos usuários em manter uma rede social.

“E o trabalho, ele te ajuda nessa forma de tu se dedicar, ir pra outro, ir pra um lugar. Ajuda que eu não vou ficar isolado, que eu não vou ficar sozinho, que eu vou estar com outras pessoas também".

“... eu converso bastante com eles. Tô toda hora conversando. (...)É bom trabalhar., eu gosto. (...) A minha mãe fala que é bom (não trabalhar) pra descansar um pouco, descansar a cabeça. Ah, mas é ruim ficar longe dos amigos, dos amigos que a gente faz".

Zanelli (2004) refere autores de linhas de raciocínio mais sociais e humanistas que compreendem a satisfação gerada pelo trabalho como resultado de experiências profissionais no meio organizacional que se disseminam para a vida social do indivíduo, podendo representar um forte indicador de influências do trabalho sobre a saúde mental, de relação entre trabalho e vida familiar ou até de interações entre trabalho e vínculos afetivos pessoais. Este conjunto de argumentos para justificar a relevância da satisfação no trabalho reflete uma concepção social segundo a qual o trabalhador satisfeito com seu trabalho pode se tornar uma pessoa com mais possibilidade de ser um cidadão integrado à sociedade, a sua família e apresentar melhores índices de bem estar físico e mental.

$\mathrm{Na}$ direção das ideias acima apresentadas, encontra-se outro sentido atribuído pelos usuários com relação ao trabalho, que é de poder auxiliar na autonomia, como expressam nas falas a seguir.

\footnotetext{
"As coisas vão ser melhores (no futuro), acho que eu vou ter uma casa, ter pessoas que gostam de mim, me ajudar, me cuidar. E pra isso ter uma renda, ter um dinheiro, possibilidade de crescimento, tanto na família, poder comprar as coisas que forem precisas, e traz motivação, porque a gente quer melhorar".

“... Não ter que depender dos outros... se eu preciso de alguma coisa ele (familiar) me dá, mas que nem aquela história, pra quê que eu preciso? Pra quê que eu quero? E eu nunca gostei disso aí, mas eu posso, não gosto de ter que dar explicação. Então é muito complicado".
}

Também em concordância com os achados da equipe, os usuários compreendem que o trabalho está diretamente ligado a uma produção de autonomia.

A ideia de autonomia vinculada ao trabalho aparece em estudo realizado por GOERCK (2009), estando associado à noção de emprego e de receber um salário que permita a sobrevivência, o 
atendimento às necessidades básicas, provendo segurança e independência, como percebemos nas falas citadas acima.

Os usuários também falam do trabalho como Ocupação da mente/

tempo. "Ali me sentia bem, saia de casa, ia pra trabalhar, me ocupava o tempo né".

"Não, acho que ajuda (trabalho), a gente não fica pensando besteira". Coincidentemente aos achados nas entrevistas com a equipe, o trabalho é entendido pelos usuários também como um meio de ocupar a mente e passar o tempo, o que nos remete novamente ao tratamento moral, já mencionado anteriormente (AMARANTE, 2007; LIMA, 2004; RESENDE, 2001), o qual se utilizava de um trabalho sem valor subjetivo e material com a finalidade de controlar pensamentos e domesticar o comportamento, por meio da ocupação do tempo.

Por outro lado, o trabalho é entendido como um meio que proporciona prazer, sendo visto como um modo de obter satisfação, prazer, relacionado ao sentimento de utilidade e de participação na vida social.

\footnotetext{
“Ah, muito bom, muito bom mesmo... é uma sensação assim... uma que tu tá ganhando e a outra de tá, eu me sinto útil, é isso aí... como é que eu vou te explicar... parece que eu to viva...".
}

O valor do trabalho se dá pelo reconhecimento conferido pelo olhar do outro e contribui de maneira considerável para a construção do sentido do trabalho. Quando há o reconhecimento, este permite dar ao sofrimento gerado pelo encontro com o trabalho, inerente a qualquer processo de trabalho, uma significação social (RENAULT, 2011). O valor do trabalho pode permitir a transformação do sofrimento em prazer, quando é reconhecido pelos outros como uma contribuição integral (GERNET; DEJ OURS, 2011). Portanto, sentir-se útil, como refere esta usuária, representa que estar trabalhando é contribuir e ser reconhecida através do olhar da sociedade.

"Ah, o prazer de servir. O prazer de estar, prazer de ser, a gente tá na sociedade. Quem é que vai dizer que eu sou louco ali, lá vendendo produtinho. Ninguém, né!" Nesta fala, o usuário traz a satisfação produzida pelo trabalho, como um meio de estar na sociedade, de alguma forma não estar excluído, ser pertencente. O usuário expressa o quanto a sociedade apresenta dificuldades em reconhecer o portador de um transtorno mental como podendo trabalhar e assim participar da vida social. Este direito muitas vezes é negado inconscientemente a essas pessoas pela crença de que são incapazes. Essa satisfação trazida acima pelo usuário nos remete ao que Gernet e Dejours (2011) trazem com relação ao envolvimento no trabalho, sendo que este pode ser um mediador insubstituível na estabilização 
e na ampliação da identidade dos sujeitos. Descrevem que o reconhecimento obtido pelo seu trabalho pode contribuir para o reconhecimento do seu saber-fazer e, assim, para o registro de sua identidade. Através do reconhecimento, trabalhar não é apenas produzir bens ou serviços, mas é também uma transformação de si mesmo.

E quando ocorre este reconhecimento, o trabalho pode favorecer 0 desenvolvimento da autoestima.

\begin{abstract}
“Então eu vi que eu podia fazer isso, que eu podia fazer isso apesar de ter a esquizofrenia, fui pensando, como seria bom pra minha vida, como seria bom pra mim. (...) E eu acho que isso é uma coisa boa mesmo, realmente as pessoas estão falando isso porque é uma coisa boa pra mim, pro meu tratamento, de eu começar um trabalho".
\end{abstract}

Esta fala expressa a importância do reconhecimento social sobre o trabalho que realiza, definindo-o como uma coisa boa, como algo que Ihe traz bem estar.

\begin{abstract}
“Então a reinserção social pra mim, através da economia solidária e do CAPS, e da oficina leva-nos a interferir, a participar da sociedade, através desses trabalhos, através desses pontos de vendas, através dessas reuniões do congresso de psicologia, do avanço da medicina e da própria terapia com o médico, já é outro discurso. Não é chegar lá: ah doutor, eu to deprimido, não consigo mais nada, doutor. Aí o doutor aumenta o remédio, não é por aí, né".
\end{abstract}

O sentido que o trabalho assume para o indivíduo que realiza determinada atividade é um aspecto extremamente relevante para a saúde mental, pois tem profunda relação com a autoimagem e autoestima, isto é, com a identidade (SELIGMANN-SILVA, 2003). O relato do usuário acima traz o quanto ele se torna sujeito do gerenciamento da sua vida, da sua saúde e até da sua doença, sendo que o trabalho lhe devolve a autoestima, um desejo de participar da sociedade, de estar inserido, de exercer sua cidadania. Programas como a Economia Solidária e a Geração de Renda são percebidos como um meio que possibilita ao usuário um espaço de desenvolvimento de suas habilidades, de reconhecimento social entre outros aspectos.

De acordo com Barfknecht (2005) nos grupos solidários, a proposta é que o trabalho seja promotor de sujeitos, da produção social da vida humana, e ao mesmo tempo, contribua para que suas produções se constituam em um espaço de criação e recriação de relações econômicas e sociais, contemplando as necessidades da grande 
maioria da população excluída, inclusive no direito à manutenção da própria vida.

Neste sentido Amarante (2007) entende que as políticas de saúde mental e atenção psicossocial passaram a adotar estratégias mais específicas e concretas, quando da criação dos projetos de geração de renda para as pessoas em acompanhamento na rede. Com as cooperativas ou empresas sociais, ou mesmo com projetos de geração de renda que incorporam os mesmos princípios das anteriores, o trabalho deixou de ser uma atividade terapêutica (prescrita, orientada, protegida), uma simples forma de ocupação do tempo ocioso ou forma de controle institucional, para se tornar uma estratégia de cidadania, autonomia e de emancipação social, criando diversas iniciativas de inclusão pelo trabalho.

\section{Considerações finais}

Os resultados obtidos com a realização da pesquisa possibilitam compreender que tanto a equipe como usuário identificam aspectos do trabalho, em comum, que favorecem a (re)inserção social, tais como: meio produtor de vínculos, auxiliar na autonomia dos usuários, como promotor da autoestima e das relações sociais. Além destes, os usuários ainda destacam que o trabalho tem um sentido de satisfação e prazer.

Destacamos que o aspecto das relações sociais pelo trabalho como forma de participar da sociedade, apontado tanto pela equipe como os usuários, vai ao encontro dos objetivos da reforma psiquiátrica enquanto valorização do sujeito como cidadão de direitos e deveres.

Em contrapartida, encontramos o entendimento de que o trabalho cumpre a função de ocupação da mente, modo de pensar bastante antigo no tratamento das doenças mentais, com a finalidade de controlar pensamentos, devaneios e domesticar o comportamento. Este modo de pensar reflete uma manutenção da condição de vida do usuário e não se apresenta como um modificador, pois, podemos dizer que ocupar a mente para não pensar na doença é também ter dificuldade para pensar como viver, apesar dela. Esta perspectiva distancia-se daquela em que o trabalho é visto como produtor de subjetividades, como agente transformador do sujeito.

Interessante que os usuários em nenhum momento apontaram aspectos que identificam o trabalho como prejudicial a sua saúde. Entretanto, a equipe trouxe esta preocupação, manifestando uma inquietação quanto ao encaminhamento do usuário para o trabalho.

A equipe problematiza a sociedade capitalista e a forma como o trabalho está posto em nossa sociedade, onde um ambiente competitivo, a intolerância com as diferenças, ritmos e desejos das pessoas, pode tornar-se um agente adoecedor e agravar ainda mais 
as condições de saúde dos usuários. Pensamos, a partir disto, que quando a equipe olha para o papel do trabalho na vida do usuário, de algum modo reflete o seu pensar sobre o trabalho na sua vida, implicando-se como trabalhadores, numa sociedade tão competitiva e ameaçadora. Desta forma, o trabalho passa a ser considerado prejudicial à saúde do usuário, tornando-se ameaçador ao benefício da aposentadoria, o qual lhes garante mínimas condições financeiras com os quais conseguem manter uma situação de vida com dignidade.

Na medida em que compreendemos que o trabalho não é só um meio de ocupação da mente, mas sim um produtor de subjetividades, este pode desempenhar a função de ser resignificante. Isto é, com o fazer, o sujeito investe na possibilidade de constituir uma nova subjetividade, um novo jeito de viver, descobre/reconhece capacidades, habilidades.

A forma como estão estabelecidas as leis nos parece ainda apresentar limitações quanto ao amparo necessário ao usuário para a fomentação da busca pela (re)inserção social pelo trabalho. Entendemos que as políticas públicas precisam ser revistas de maneira a criar soluções para as dificuldades encontradas pela equipe, usuários e familiares com relação a uma estabilidade financeira que garanta segurança, sustento e possibilidades de bem estar. Pensamos que, como forma de incentivo, devesse ser instituído em termos de legislação, um período como se fosse um estágio, em que mesmo em atividade laboral o usuário permanecesse com a garantia de receber seu benefício.

Entendemos que no contexto atual a via para fomentar e preservar a (re)inserção social pelo trabalho seja através de Programas existentes em algumas organizações que têm uma visão de valorização das diferenças, assim como, o de Geração de Renda e Trabalho e das formas distintas da Economia Solidária. Estes programas zelam por uma maneira de trabalhar que incentiva a criatividade, a produção de subjetividade e o resgate pela cidadania, princípios que estão nos fundamentos da Reforma Psiquiátrica.

Com este trabalho buscamos proporcionar à equipe multiprofissional um espaço para pensar e problematizar a questão do trabalho junto aos usuários e o meio social. Exercício que precisa ser constante, buscando integrar os desejos do usuário com as atividades laborais, valorizando o trabalho como uma dimensão da vida social.

Acreditamos que novas pesquisas devam ser realizadas, com a proposta de investigar a trajetória dos usuários no processo de (re)inserção social por meio do trabalho. Propomos às equipes, usuários e aos familiares, refletir sobre o sentido do trabalho e a forma como este pode trazer benefícios à vida de cada um. A (re)inserção social pelo trabalho precisa ser problematizada por todos os envolvidos, a fim de proporcionar novas descobertas, novas 
subjetividades, alterando a história dos sujeitos e proporcionando vivências autênticas de produção de si.

\section{Referências}

AMARANTE, Paulo. Saúde mental e atenção psicossocial. Rio de J aneiro: Fiocruz, 2007.

BARDIN, Laurence. Análise de conteúdo. Trad. Luís Antero Reto e Augusto Pinheiro. Lisboa: Edições 70, 2002.

BARFKNECHT, K. S. Economia solidária, saúde mental e trabalho em uma cooperativa de confecção de Porto Alegre. 2005. $137 \mathrm{f}$. Dissertação (Mestrado em Psicologia Social) - Instituto de Psicologia , Universidade Federal do Rio Grande do Sul (UFRGS), Porto Alegre. Disponível em: <http://www.lume. ufrgs.br/bitstream/handle/10183/5000/00050770 0 . pdf? sequence $=1>$. Acesso em 27 de nov. de 2011 .

BRASIL. Lei Federal $n^{\circ} 8080$ de 19 de setembro de 1990. Dispõem sobre as condições para a promoção, proteção e recuperação da saúde, sobre a organização e o funcionamento dos serviços correspondentes. Brasília, DF, 1990. Disponível em: <http://www. planalto.gov.br/ccivil_03/Leis/L8080.htm>. Acesso em 27 out. de 2011.

BRASIL. Secretaria de Atenção à Saúde. Ministério Público. Portaria Interministerial no 224, de 29 de janeiro de 1992. Estabelece diretrizes e normas para o atendimento em saúde mental. Brasília, DF, $1992 . \quad$ Disponível em: <http://www.saude.mg.gov.br/atos_normativos/legislacaosanitaria/estabelecimentos-de-saudē/saudemental/PORTARIA_224.pdf>. Acesso em 20 out. de 2011.

BRASIL. Resolução no 196, de 10 de outubro de 1996. Dispõe sobre as diretrizes e normas de pesquisa envolvendo seres humanos. Conselho Nacional de saúde. Brasília, DF, out. 1996. Disponível em: <www.ufrgs.br/bioetica/res19696.htm>. Acesso em 17 nov. 2011.

BRASIL. Ministério da Saúde. Secretaria de Atenção à saúde. Departamento da Ações Programáticas Estratégicas. Saúde mental e economia solidária: inclusão social pelo trabalho. Editora MS: Brasília, DF, 2005.

BRASIL. Ministério da Saúde. Saúde mental e economia solidária: inclusão social pelo trabalho. Balanço da Política, Análise da Expansão da Rede Brasileira de Saúde Mental e Economia Solidária e Agenda para os Próximos anos. Brasília, DF, 2011. Disponível em:

<http://portal.saude.gov.br/portal/arquivos/pdf/polit_mental_econ_s oli.pdf>. Acesso em 15 de set. de 2011.

CANGUILHEM, G. O normal e o patológico. Rio de Janeiro: Forense Universitária, 2009. 
CATTANI, A. D.; HOLZMANN, L. Dicionário de trabalho e tecnologia. Porto Alegre: EdUFRGS, 2006.

DEJ OURS, C.; ABDOUCHELI, E.; J AYET C.; STTOCO, M. I. (Coord.). A psicodinâmica do trabalho: contribuições da escola Dejouriana à análise da relação prazer, sofrimento e trabalho. São Paulo: Atlas, 1994.

GERNET, I.; DEJOURS, C. Avaliação do trabalho e reconhecimento. In: BENDASSOLLI, P. F.; SOBOLL, L. A. P. (Org.). Clínicas do trabalho: novas perspectivas para compreensão do trabalho na atualidade. São Paulo: Editora Atlas, 2011.

GOERCK, Caroline. Programa de economia solidária em desenvolvimento: sua contribuição para a viabilidade das experiências coletivas de geração de trabalho e renda no Rio Grande do Sul. 2009. 405 f. Tese (Doutorado em Serviço Social) - Faculdade de Serviço Social, Pontifícia Universidade Católica/RS (PUCRS), Porto Alegre,2009. Disponível em: <http://www.fbes.org.br/biblioteca22/tese_caroline.pdf>. Acesso em 20 de out. de 2011

HIRDES, Alice. Reabilitação psicossocial: dimensões teóricopráticas do processo. Erechim: Edifapes, 2001.

LIMA, E. A. Oficinas em saúde mental: percurso de uma história, fundamento de uma prática. In: COSTA, C. M.; FIGUEIREDO, A. C. (Org.). Oficinas terapêuticas em saúde mental: sujeito, produção e cidadania. Rio de Janeiro: Contra Capa, 2004; p. 282.

LUSSI, I. A. O.; MATSUKURA, T. S.; HAHN, M. S. Reabilitação psicossocial: oficinas de geração de renda no contexto da saúde mental. O Mundo da Saúde, São Paulo, v. 34, n. 2, p. 284-90, abril/junho 2010.

RENAULT, E. Souffrances socials. Philosophie, psychologie et politique. Paris: La Découverte, 2008. Apud BENDASSOLLI, P. F.; SOBOLL, L. A. P. (Org.). Clínicas do trabalho: novas perspectivas para compreensão do trabalho na atualidade. São Paulo: Editora Atlas, 2011.

RESENDE, Heitor. Política de Saúde mental no Brasil: uma visão histórica. In: TUNDIS, S. A.; COSTA, N. R. (Org.). Cidadania e loucura: políticas de saúde mental no Brasil. Petrópolis: Vozes, 2001, p. 15-74.

RODRIGUES, R. C.; MARINHO, T. P. C.; AMORIM, P. Reforma Psiquiátrica e Inclusão Social pelo Trabalho. Ciência \& Saúde Coletiva, v. 15, suplemento1, p. 1615-25, jan./jun. 2010.

SANTIAGO, E.; YASUI, S. O trabalho como dispositivo de atenção em saúde mental: trajetória histórica e reflexões sobre a sua atual utilização. Revista da Psicologia da UNESP, São Paulo, v. 10, n. 1, p. $195-210,2011$. 
SELIGMANN-SILVA, Edith. Psicopatologia e Saúde Mental no Trabalho. In: MENDES, R. (Org.). Patologia do Trabalho. 2ed. São Paulo: Editora Atheneu, 2003.

WORLD MEDICAL ASSOCIATION DECLARATION OF HELSINKI. Ethical principles for medical research involving human subjects. 59th WMA General Assembly, Seoul, October 2008. Disponível em: <http://www.wma.net/en/30publications/10policies/b3/index.html>. Acesso em 21 nov. de 2011.

ZANELLI, J. C.; BORGES-ANDRADE, J. E.; BASTOS, A. V. B. (Org.). Psicologia, organizações e trabalho no Brasil. Porto Alegre: Artmed, 2004.

\section{Endereço para correspondência \\ Kelen Patrícia Bürke}

Laboratório de Psiquiatria Molecular

Hospital de Clínicas de Porto Alegre - Centro de Pesquisas/Centro de Pesquisas Clínicas

Rua Ramiro Barcelos, 2350 - CEP: $90035-903$ - Porto Alegre/RS, Brasil.

Endereço eletrônico: kelenpatricia@yahoo.com.br

\section{Desirée Luzardo Cardozo Bianchessi}

Hospital de Clínicas de Porto Alegre - Serviço de Psicologia Rua Ramiro Barcelos, 2350 - CEP 90035-903 - Porto Alegre/RS, Brasil.

Endereço eletrônico: desiluzardo@gmail.com

Recebido em: 24/05/2012

Reformulado em: 19/09/2013

Aceito para publicação em: $27 / 11 / 2013$

Acompanhamento do processo editorial: Rita Maria Manso de Barros

\section{Notas}

* Psicóloga Residente da Residência Multiprofissional Integrada em Saúde, ênfase em Saúde Mental, Hospital de Clínicas de Porto Alegre, Porto Alegre/RS.

** Psicóloga Ms Contratada do Hospital de Clínicas de Porto Alegre, Porto Alegre/RS. 